\title{
Is There a Role for HTLV-1-Specific CTL in Adult T-Cell Leukemia/Lymphoma?
}

\author{
Aileen G. Rowan and Charles R. M. Bangham \\ Department of Immunology, Wright-Fleming Institute, Imperial College London, London W2 1PG, UK \\ Correspondence should be addressed to Aileen G. Rowan, a.rowan@imperial.ac.uk
}

Received 31 August 2011; Accepted 27 September 2011

Academic Editor: Mineki Saito

Copyright ( $) 2012$ A. G. Rowan and C. R. M. Bangham. This is an open access article distributed under the Creative Commons Attribution License, which permits unrestricted use, distribution, and reproduction in any medium, provided the original work is properly cited.

\begin{abstract}
ATLL is an aggressive malignancy of T cells that affects about $5 \%$ of individuals infected with HTLV-1. The precise mechanism of oncogenesis is not known, but there is evidence that two regulatory viral proteins, Tax and HBZ, are involved. A high set point proviral load is associated with development of ATLL or a chronic inflammatory condition, HAM/TSP. Several lines of evidence, including HLA class 1 association studies and in vitro killing assays, indicate that cytotoxic T lymphocytes are instrumental in determining this proviral load set point. Prior studies have focused chiefly on the CTL response to the immunodominant Tax protein: efficient lysis of Tax-expressing cells inversely correlates with proviral load in nonmalignant infection. However, a recent study showed that strong binding of peptides from HBZ, but not Tax, to HLA class 1 molecules was associated with a low proviral load and a reduced risk of developing HAM/TSP, indicating an important role for HBZ-specific CTL in determining infection outcome. In comparison with nonmalignant infection, HTLV-1-specific CTLs in ATLL patients are reduced in frequency and functionally deficient. Here we discuss the nature of protective CTL responses in nonmalignant HTLV-1 infection and explore the potential of CTLs to protect against ATLL.
\end{abstract}

\section{Introduction}

Human T-cell lymphotropic virus-1 (HTLV-1) is a retrovirus which predominantly infects $\mathrm{CD} 4^{+} \mathrm{T}$ cells, where it is reverse transcribed and integrates into host DNA. The integrated provirus can then disseminate by de novo infection of $\mathrm{T}$ cells via the virological synapse, or by inducing clonal expansion of the host cell. Most infected individuals do not experience any symptoms, and HTLV-1-associated disease is rarely observed in individuals with a proviral load of less than $1 \%$ of their peripheral blood mononuclear cells (PBMCs) [1]. Approximately $2-6 \%$ of individuals HTLV-1 develop adult T-cell leukemia/lymphoma (ATLL), and a slightly lower percentage suffer from inflammatory disorders, including HTLV-1-associated myelopathy/tropical spastic paraparesis (HAM/TSP). ATLL is a highly aggressive T-cell malignancy with a poor prognosis, and, even with standard treatment, the median survival time for clinically acute forms of the disease is measured in months $[2,3]$. Chemotherapeutic intervention has had limited efficacy despite the develop- ment of drugs to specifically target ATLL cells, though some improvement has been reported combining antiviral drugs (zidovudine) and immunomodulators (such as type-1 interferon) [3-5]. Allogeneic hematopoietic stem cell transplantation (HSCT) has also improved survival [6], though may not be a viable treatment option in all cases due to the advanced age of most ATLL patients and the lack of suitable donors [2]. Thus, the ability to harness the host immune system to control ATLL would be an attractive proposition.

Leukemic cells carry at least one copy of the provirus, and express CD4, the IL-2 receptor alpha chain CD25, and typically exhibit a flower-like multilobed nucleus and genetic abnormalities. Downregulation of $\mathrm{CD} 3$ and $\mathrm{CD} 7$ on leukemic cells has been described [7], and several groups have detected FoxP3 protein in ATLL cells [7-9], although the degree of expression of FoxP3 varies between patients. There is conflicting evidence on whether FoxP3-expressing leukemic cells have regulatory capacity $[9,10]$. ATLL is also characterized by uncontrolled expansion of $\mathrm{T}$ cells which 
share a common $\mathrm{T}$-cell receptor- $\mathrm{V} \beta$ chain, implying that the disease is a result of malignant transformation and expansion of a small number of infected cells. High-throughput quantitative sequencing of the site of proviral integration reveals that the bulk of the proviral load in ATLL patients is composed of highly abundant clones with a small number of unique proviral integration sites. This contrasts with asymptomatic carriers (ACs) of the virus and patients with HAM/TSP, whose infected cells consist of a mixture of T-cell clones carrying many unique integration sites with varying abundance in the peripheral blood [11].

$\mathrm{CD}^{+}$cytotoxic T lymphocyte (CTL) recognition of viral peptides presented in the context of the human leukocyte antigen (HLA) class 1 (major histocompatibility (MHC) protein class 1) triggers cytokine production by the CTL and lysis of the infected cell. The affinity and stability of the interaction between a given TCR and peptide-MHC complex must exceed a threshold level to allow initial activation of the $\mathrm{T}$ cell and to induce clonal expansion to form effector and memory $\mathrm{T}$ cells. The nature of a CTL response to its cognate antigen can subsequently be modulated by cell-intrinsic and cell-extrinsic factors, which include the concentration of peptide-MHC complexes on the target cell surface, the length of time which has passed since the CTL has encountered antigen, expression of the peptide-MHC-TCR-stabilizing CD8 co-receptor, inhibition by regulatory $\mathrm{T}$ cells, and the cytokine microenvironment. Thus, the efficiency of CTL control is determined by a combination of the host genotype and environmental factors.

HTLV- 1 antigens are expressed in vivo and induce a CTL response. In particular, the viral transcription factor Tax is widely recognized by CTLs, and abundant activated Taxspecific CTL can be detected in most infected individuals [12-15]. Tax is expressed early in the life cycle of the virus (ex vivo data) and can induce proliferation of infected cells, but also expression of other viral genes, and contains several well-characterized CTL epitopes. CTL epitopes and CTLs specific for other viral genes have been described; though Tax is immunodominant $[12,16]$, efficient recognition of other subdominant target antigens appears to be more important in protection: see what follows.

Little is known about the role of HTLV-1-specific CTL in preventing or resolving ATLL. There is anecdotal evidence that immune control of ATLL is achievable: spontaneous regression of ATLL is sometimes observed. One report documents such a patient, in which regression coincided with acquisition of an ability of their PBMCs to kill an ATLL cell line in vitro. Subsequent disease progression was accompanied by a decline in the ability of their PBMC to lyse ATLL cells [17]. Furthermore, there have been several reports of ATLL emergence in HTLV- $1^{+}$individuals after immune suppressive treatment during liver [18] and renal [19] transplantation, indicating the importance of continuous immune surveillance in infected individuals in suppression of ATLL development.

In this paper, we review

(i) what is known about the HTLV-1-specific CTL response in ATLL patients; (ii) properties of HTLV-1 specific CTLs in patients who have a low proviral load;

(iii) the role of HLA class 1 genes in CTL control of HTLV1 ;

(iv) expression of CTL target antigens by ATLL cells.

\section{HTLV-1-Specific CTL Response in ATLL Patients}

Few data have been published describing the functional properties of CTLs in ATLL, but all reports agree that the ex vivo CTL response to HTLV-1 antigens is weak in these patients [20]. Using a panel of peptide-MHC tetramers Kozako et al. found that, in comparison with asymptomatic individuals, Tax-specific CTLs in ATLL patients were directed at a narrower range of epitopes and present at lower frequencies or were undetectable ex vivo [21]. Env-specific CTLs were also detected but were present at low frequencies and only in asymptomatic carriers. Expression of the programmed death-1 (PD-1) receptor, which delivers inhibitory signals to the CTL, was slightly higher on virus-specific CTLs in ATLL patients than in ACs [22]. A subset of ATLL patients have no detectable CTL when PBMCs are assayed directly ex vivo. After culture, however, functional CTL are sometimes observed [23, 24]: efficient killing of ATLL cells can be demonstrated by $\mathrm{CD} 8^{+} \mathrm{T}$ cells after being cultured in vitro for a week in the presence of IL-2 and a polyclonal activator or stimulated with HLA-matched infected cells [23, 24].

In peripheral blood of acute ATLL patients, the lymphocyte population consists predominantly of leukemic $\mathrm{CD} 4{ }^{+} \mathrm{CD} 25^{+}$cells. Careful analysis revealed that although the ratio of $\mathrm{CD}^{+}: \mathrm{CD}^{+} \mathrm{T}$ cells is grossly elevated, the absolute number of $\mathrm{CD}^{+} \mathrm{T}$ cells detected in peripheral blood is similar to the normal range or reduced by a factor of two $[20,23]$. Thus, depletion of the $\mathrm{CD}^{+} \mathrm{T}$-cell subset does not explain the reduced CTL activity observed. A more likely candidate mechanism to explain this phenomenon is suppression by regulatory $\mathrm{T}$ cells. Uninfected $\mathrm{FoxP}^{+} \mathrm{T}$ cells with regulatory activity are significantly expanded in ATLL patients, and lysis of autologous-infected cells by uncultured CTLs was inversely proportional to the frequency of FoxP3 ${ }^{+}$ cells [9]. It is also possible that competition from ATLL cells for resources such as growth factors and cytokines, for example, IL-2, disrupts the antiviral CTL response.

Despite the observed deficiency in the CTL response to HTLV-1 in ATLL, there is evidence for an efficient immune response in a subset of ATLL patients. In three individuals with ATLL, Furukawa et al. observed an amino acid change within the CTL epitope Tax [11-19] which rendered Tax unrecognizable to CTLs specific for the consensus epitope [25]. In addition, premature stop codons within the tax gene which abrogate its transactivating activity were observed in another ATLL patient. Familial analysis revealed that the mutation emerged after viral transmission [25], strongly implying that immune selection favoured the variant genes. Loss of Tax expression or activity has the downstream effect of reduced expression of other viral genes such as gag, pol, and $e n v$ which are transactivated by Tax. Thus, by ablating 
TABLE 1: HBZ and Tax as CTL target antigens: genetics, expression, and antigenicity in ATLL.

\begin{tabular}{|c|c|c|}
\hline & $\operatorname{Tax}$ & $\mathrm{HBZ}$ \\
\hline \multicolumn{3}{|c|}{$\begin{array}{l}\text { Naturally occurring genetic and epigenetic } \\
\text { changes in ATLL }\end{array}$} \\
\hline Point mutations & Detected in Tax 11-19 A*0201 epitope [25] & None described \\
\hline \multirow[t]{2}{*}{ Deletions } & Premature stop codons $[26]$ & None described \\
\hline & Deletions of $5^{\prime}$ end of genome $[25,27,28]$ & \\
\hline Epigenetic silencing & $\begin{array}{l}\text { Hypermethylation of } 5^{\prime} \text { LTR }[46,59,60] \text { and } \\
\text { pX region }[59]\end{array}$ & None described \\
\hline \multicolumn{3}{|l|}{ Expression in ATLL } \\
\hline In vivo & mRNA and protein low/undetectable $[45,46]$ & $\begin{array}{l}\text { Multiply spliced isoforms of mRNA } \\
\text { detected }[51,52]\end{array}$ \\
\hline \multirow[t]{2}{*}{ Ex vivo cultures } & $\begin{array}{l}\text { Increased mRNA transcription in vitro } \\
\text { culture [54] }\end{array}$ & $\begin{array}{l}\text { Increased mRNA transcription after } \\
\text { culture in vitro [54] }\end{array}$ \\
\hline & Protein detected in $50 \%$ of ATL cases [44] & $\begin{array}{l}\text { Protein at threshold for detection using } \\
\text { currently available antibodies [53] }\end{array}$ \\
\hline \multicolumn{3}{|l|}{ CTL response in $A C$ and $H A M / T S P$} \\
\hline CTL response in vivo & $\begin{array}{l}\text { High frequencies Tax-specific CTL detected } \\
\text { in } 66-94 \% \text { infected individuals }[12,15,43]\end{array}$ & $\begin{array}{l}\text { Low frequencies of HBZ-specific CTL } \\
\text { detectable in } 25-40 \% \text { of individuals } \\
{[42,43]}\end{array}$ \\
\hline Immunogenicity for CTL & $\begin{array}{l}\text { Immunodominant, HTLV-1 protein most } \\
\text { frequently recognized by CTL [12-14] }\end{array}$ & 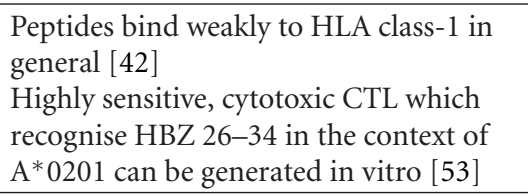 \\
\hline Potential for protection in ATLL & $\begin{array}{l}\text { Enhanced ability to present Tax peptides } \\
\text { does not confer a significant protective effect } \\
{[42] \text { but can lyse ATL cells expressing Tax in }} \\
\text { vitro }[23,24]\end{array}$ & $\begin{array}{l}\text { Efficient presentation of HBZ peptides } \\
\text { significantly associated with low PVL and } \\
\text { remaining asymptomatic [42] }\end{array}$ \\
\hline
\end{tabular}

a single viral protein, the infected cell may also escape surveillance by CTL specific for other viral proteins. This tax mutation was not restricted to ATLL patients, but was also detectable in a minor population of infected cells in ACs and patients with HAM/TSP [26]. There is further evidence of large deletions within the HTLV-1 genome in dominant ATLL clones. In particular, the $5^{\prime}$-long terminal repeat (LTR) region, which encodes the promoter that drives expression of the tax gene, is deleted in $28 \%$ of ATLL patients, compared with $4 \%$ ACs $[25,27,28]$. It is less clear whether these large deletions are due to immune selection or to an inherent genetic instability of the leukemic cells (see Table 1).

\section{CTL Control of HTLV-1 Proviral Load}

Analysis of HTLV-1-specific CTL responses in individuals who do not develop disease may provide important clues as to the character of a desirable CTL response in ATLL. In cases of nonmalignant infection, proviral load can vary by up to 1000 -fold between individuals, though within an individual the load usually remains stable over years of infection. In addition, ACs with a viral load above $1 \%$ are significantly more likely to develop inflammatory disease [1, 29]. Thus, we identify a successful immune response as one that results in a low proviral load set point. Many methods have been employed to quantify the frequency of HTLV1-specific CTLs: primarily identifying cells by functional assays or directly staining reactive TCRs using fluorochromelabelled peptide-MHC tetramers. However, simply measuring the frequency of HTLV-1-specific CTLs has revealed a positive, negative, or zero correlation with proviral load in different studies [30-32]. This is not an unexpected finding in persistent infection [33], where chronic antigen exposure can drive proliferation of CTLs which are not protective and may even be detrimental in the case of HTLV1 -associated inflammatory disorders. Thus, the absolute frequency of HTLV-1-specific CTLs may not be informative, and alternative methods of quantification of CTL efficiency are desirable.

We have developed a method to quantify the efficiency with which uncultured $\mathrm{CD}^{+}$cells suppress Tax expression in autologous infected $\mathrm{CD} 4^{+} \mathrm{T}$ cells in a perforin-dependent and MHC class-I-restricted manner. $\mathrm{CD} 8^{+}$-depleted PBMCs are mixed with autologous $\mathrm{CD}^{+} \mathrm{T}$ cells at a range of effector: target ratios and cocultured overnight, following which the number of Tax-expressing cells is enumerated by flow cytometry, and the rate of elimination of Taxexpressing cells is estimated by using nonlinear regression to fit a mathematical model [34]. Using this assay, we have found that the rate of elimination of Tax-expressing cells is inversely proportional to proviral load, suggesting that a more efficient CTL response has the effect of lowering proviral load [34]. The CTL efficiency parameter measured by this assay could explain up to $50 \%$ of the observed 
variation among infected individuals in proviral load [34]. Although the precise epitope specificity of CTLs responsible for elimination of Tax-expressing cells is not defined in this assay, we also observed that the rate of infected cell elimination is proportional to the sensitivity with which Taxspecific CTLs detect peptides presented on target cells and that naturally infected cells expressing high levels of Tax protein are killed significantly faster than cells expressing lower levels of Tax [35]. These observations indicate that Tax-specific CTLs can eliminate autologous cells which begin to express the provirus. This is not just a phenomenon observed in cells cultured in vitro: in vivo, $\mathrm{CD} 4^{+} \mathrm{CD} 45^{+} \mathrm{RO}$ cells (which comprise most Tax-expressing cells) proliferate faster in infected individuals than in uninfected individuals and tend to die faster in HTLV-1-infected people [36]. Taken with the observation that, in ACs and patients with HAM/TSP, proviral load is relatively stable over years of infection [11], these data are consistent with the existence of a dynamic equilibrium between proviral expression and CTL surveillance, in which the per-cell efficiency of CTLs is a major determinant of the proviral load set point.

\section{HLA Class 1 and the Immune Response to HTLV-1}

Some of the most powerful and compelling evidence for the important role of CTLs in controlling HTLV-1 comes from genetic studies. In 1999, Jeffery et al. provided the first definitive evidence that HLA class 1 genes can be protective in HTLV-1 infection [37]. They observed that asymptomatic individuals who possessed HLA-A*02 alleles had a proviral load which was approximately one third that of individuals who lacked HLA-A*02. In addition, the chance of developing HAM/TSP was halved in HLA-A* $02^{+}$individuals. HLA-A* 02 is a common and highly polymorphic allele, present at high frequencies in most populations. HLA-A*0201 binds the Tax 11-19 epitope with extremely high affinity, and up to $10 \%$ of circulating CTLs can be specific for this epitope [38]. In ATLL, Yashiki et al. reported that the HLA class 1 alleles HLA-A*26, HLA-B*4002, HLA-B*4006, and HLA-B*4801 were more abundant in individuals who develop ATLL in comparison with AC [39]. They hypothesize that this is due to a reduced ability to bind and present Tax peptides, due to the inability of these alleles to bind anchoring residues in peptides derived from Tax [39].

Although Tax is both expressed and frequently targeted by CTL in HTLV-1 infection, a recent genetic study has shifted the focus of attention to another viral protein: HTLV1 basic leucine zipper protein (HBZ) [40]. HLA association studies are hampered by the heterogeneity of HLA class 1 alleles in a population. Thus, for rare alleles that may be protective, large numbers of participants are required in a given study for associations to reach statistical significance, and the results may only apply to certain populations. Also, association studies do not reveal the precise mechanism of protection these alleles confer. As an alternative approach, MacNamara et al. conducted a systematic study that tested the capacity of an individual's HLA alleles to bind HTLV-1 peptides and asked whether this metric correlated with the proviral load and the "risk" (i.e., relative prevalence) of HAM/TSP. They used experimentally validated epitope prediction software [41] which predicted the affinity of binding of peptides derived from the HTLV-1 genome to HLA-A and -B alleles in a cohort of 202 ACs and 230 patients with HAM/TSP [42]. They found that the known protective alleles $A^{*} 0201$ and $C^{*} 0801$ bound peptides from HBZ with significantly higher affinity than alleles which were associated with disease progression ( $\left.B^{*} 5401\right)$. Further analysis showed that in general ACs had HLA alleles which bound peptides from HBZ significantly more strongly than patients with HAM/TSP, and this was not attributable simply to $A^{*} 0201$, $\mathrm{C}^{*} 0801$, and $\mathrm{B}^{*} 5401$. The more alleles an individual possessed that strongly bound peptides from HBZ, the lower their proviral load. Interestingly, despite the strong protective effect of effective HBZ presentation, peptides from HBZ bound to class 1 molecules with significantly lower affinity than peptides from Tax. These data were unexpected but robust, and although CTL specific for HBZ could only be detected at low frequencies in $25-40 \%$ of infected individuals [42, 43], a CTL clone specific for HBZ could efficiently kill HLA-matched primary HTLV-1-infected $\mathrm{CD} 4{ }^{+} \mathrm{CD} 25^{+}$cells, indicating that peptides derived from HBZ are presented by naturally infected cells [42].

\section{Expression of CTL Target Antigens by ATLL Cells}

Viral antigen expression by ATLL cells in vivo is of course the critical determinant of their susceptibility to lysis by HTLV-1-specific CTL (see Table 1). Although the Tax protein is strongly expressed in cultured cells of $\sim 50 \%$ of ATLL cases [44], Tax mRNA is typically undetectable or present at extremely low copy number in peripheral blood $[45,46]$. Despite this, ATLL cells which were immediately fixed ex vivo were sufficient to induce a Tax-specific CTL response when used to immunize rats [44]. These data suggest that CTLs are more sensitive than antibody staining in detecting protein expression and lack of detection of mature protein expression does not preclude the presentation of peptides in vivo. A rat model of ATLL in which HTLV-1-transformed cell lines are adoptively transferred into an immunodeficient host has generated data which supports a role of Tax-specific CTL response in prophylaxis against disease development. Immunization with a DNA vaccine encoding full-length Tax protein or with Tax oligopeptides protects against development of a lymphoproliferative disorder in this model [47, 48]. Similarly, adoptive transfer of Tax-specific CTLs was also sufficient to prevent disease [47]. Interestingly, epitopes from Tax are also presented and targeted by newly expanded CTLs in vivo in ATLL patients who have undergone successful HSCT $[49,50]$.

HBZ is emerging as an alternative viral target antigen in ATLL. Uniquely among HTLV-1 transcripts, several variably spliced isoforms of HBZ mRNA are readily detectable in vivo in all HTLV-1 $1^{+}$individuals tested [51]. The negative strand of the $3^{\prime}$ genomic region of HTLV-1, from which 
HBZ is transcribed, is uniformly conserved in all ATLL cases $[28,52]$, implying an essential role of HBZ in ATLL persistence, but also making it an attractive target for immunotherapy. The ratio of HBZ mRNA to Tax mRNA is significantly higher in ATLL patients than in patients with HAM/TSP or ACs [51] which may be accounted for by the silencing of Tax by mutation, deletion, or methylation of the Tax-encoding DNA frequently observed in ATLL. Like Tax, however, expression of HBZ protein is usually undetectable in HTLV-1 ${ }^{+}$PBMCs directly ex vivo. Currently available antibodies reveal extremely low expression of HBZ in cultured, naturally infected cells [53]. Evidence from several groups suggests that HBZ protein is likely to be expressed at lower levels than Tax [53] (Rowan, Bangham, unpublished observations), and the majority of the HBZ mRNA is retained in the nucleus [54], which may inhibit its translation. Suemori et al. performed an elegant study which tested the activity of an in vitro generated CTL clone specific for HBZ 24-36 in the context of $A^{*} 0201$. They showed that sensitive, efficient CTLs specific for HBZ could be generated, at least in $\mathrm{A}^{*} 0201^{+}$individuals, despite the low binding affinity of HBZ peptides for HLA class 1 . These cells could lyse HLA-matched HBZ-transfected or peptide-loaded cells, but not freshly isolated ATLL cells in vitro [53]. More testing is needed to ascertain the contribution of HBZ-specific CTLs in controlling proviral load in vivo, and the rat model of leukemogenesis provides one possible system in which to address this question.

\section{Discussion}

It is clear that the CTL response is crucial in maintaining a low proviral load in nonmalignant cases of HTLV-1 infection. It is also evident that the CTL response to HTLV1 proteins in ATLL is somewhat lacking, with a reduced frequency of HTLV-1-specific CTLs, a reduced number of viral epitopes targeted, and CTL functional defects. Enhancing weak CTL responses could be a potentially effective, specific method for controlling ATLL: the epitopes are expressed only by infected T cells, and efficient HTLV1-specific CTLs can provide surveillance for the lifetime of the host; this could be achieved by therapeutic vaccination. In addition, induction or enhancement of HTLV-1-specific CTLs in people at risk of developing ATLL could prevent disease development. Key considerations in designing a vaccine include the choice of antigen, method of delivery, and the need to surmount whatever mechanisms result in a weak HTLV-1-specific CTL response in individuals who develop ATLL. Tax and HBZ are emerging as the key target antigens to be included in a CTL-directed vaccine. Interestingly, both Tax and HBZ have been implicated in the initiation of leukemogenesis, reviewed in $[55,56]$, and inclusion in a putative vaccine would require functional inactivation of both of these proteins. In fact, several vaccine constructs designed to induce Tax-specific CTLs have already been successfully tested in animal models $[57,58]$. HBZ, though less well characterized, plays an indispensable role in maintenance of ATLL cells [52], and the region of the HTLV-1 genome which encodes HBZ appears to be essential as it is preferentially protected from deletion. Since HBZ is constitutively expressed in vivo and ranks as the most protective CTL target antigen in nonmalignant infection, targeting HBZ could be the most important component of a vaccine, particularly for ATLL. It seems logical to target both proteins in order to exploit both the antigenicity of Tax and the potentially highly protective properties of HBZ-specific CTLs. Targeting epitopes from other HTLV-1 proteins may also be beneficial in ATLL; however, no experimental data has been published which supports or indeed refutes this. Finally, it may be advantageous to consider combining therapeutic vaccination with chemotherapeutic ablation of ATLL cells, to increase the effective CTL: target ratio, enabling the CTLs to regain control of the malignancy.

\section{Acknowledgments}

The authors would like to thank Drs. Lucy Cook, Yorifumi Satou, Becca Asquith, Graham Taylor, and Mineki Saito for advice and helpful discussion. They also thank the Wellcome Trust for funding. Finally, they would like to thank all of the individuals who donated blood which allowed this work to be carried out.

\section{References}

[1] M. Nagai, K. Usuku, W. Matsumoto et al., "Analysis of HTLV-I proviral load in $202 \mathrm{HAM}$ /TSP patients and 243 asymptomatic HTLV-I carriers: high proviral load strongly predisposes to HAM/TSP," Journal of NeuroVirology, vol. 4, no. 6, pp. 586593, 1998.

[2] M. Shimoyama, "Diagnostic criteria and classification of clinical subtypes of adult T-cell leukaemia-lymphoma. A report from the lymphoma study group (1984-1987)," The British Journal of Haematology, vol. 79, no. 3, pp. 428-437, 1991.

[3] A. Bazarbachi, Y. Plumelle, J. Carlos Ramos et al., "Metaanalysis on the use of zidovudine and interferon-alfa in adult T-cell leukemia/lymphoma showing improved survival in the leukemic subtypes," Journal of Clinical Oncology, vol. 28, no. 27, pp. 4177-4183, 2010.

[4] P. S. Gill, W. Harrington, M. H. Kaplan et al., "Treatment of adult T-cell leukemia-lymphoma with a combination of interferon alfa and zidovudine," The New England Journal of Medicine, vol. 332, no. 26, pp. 1744-1748, 1995.

[5] O. Hermine, D. Bouscary, A. Gessain et al., "Brief report: treatment of adult T-cell leukemia-lymphoma with zidovudine and interferon alfa," The New England Journal of Medicine, vol. 332, no. 26, pp. 1749-1751, 1995.

[6] M. Kami, T. Hamaki, S. Miyakoshi et al., "Allogeneic haematopoietic stem cell transplantation for the treatment of adult T-cell leukaemia/lymphoma," The British Journal of Haematology, vol. 120, no. 2, pp. 304-309, 2003.

[7] Y. Tian, S. Kobayashi, N. Ohno et al., "Leukemic T cells are specifically enriched in a unique $\mathrm{CD} 3^{\text {dim }} \mathrm{CD} 7^{\text {low }}$ subpopulation of $\mathrm{CD}^{+} \mathrm{T}$ cells in acute-type adult T-cell leukemia," Cancer Science, vol. 102, no. 3, pp. 569-577, 2011.

[8] M. Abe, K. Uchihashi, T. Kazuto et al., "Foxp3 expression on normal and leukemic $\mathrm{CD} 4{ }^{+} \mathrm{CD} 25^{+} \mathrm{T}$ cells implicated in human T-cell leukemia virus type-1 is inconsistent with Treg cells," European Journal of Haematology, vol. 81, no. 3, pp. 209217, 2008. 
[9] F. Toulza, K. Nosaka, M. Takiguchi et al., "FoxP3+ regulatory $\mathrm{T}$ cells are distinct from leukemia cells in HTLV-1-associated adult T-cell leukemia," International Journal of Cancer, vol. 125, no. 10, pp. 2375-2382, 2009.

[10] S. Chen, N. Ishii, S. Ine et al., "Regulatory T cell-like activity of Foxp3+ adult T cell leukemia cells," International Immunology, vol. 18, no. 2, pp. 269-277, 2006.

[11] N. A. Gillet, N. Malani, A. Melamed et al., "The host genomic environment of the provirus determines the abundance of HTLV-1-infected T-cell clones," Blood, vol. 117, no. 11, pp. 3113-3122, 2011.

[12] P. K. C. Goon, A. Biancardi, N. Fast et al., "Human T Cell Lymphotropic virus (HTLV) type-1-specific $\mathrm{CD}^{+} \mathrm{T}$ cells: frequency and immunodominance hierarchy," Journal of Infectious Diseases, vol. 189, no. 12, pp. 2294-2298, 2004.

[13] S. Jacobson, H. Shida, D. E. McFarlin, A. S. Fauci, and S. Koenig, "Circulating $\mathrm{CD}^{+}$cytotoxic $\mathrm{T}$ lymphocytes specific for HTLV-I pX in patients with HTLV-I associated neurological disease," Nature, vol. 348, no. 6298, pp. 245-248, 1990.

[14] M. Kannagi, S. Harada, I. Maruyama et al., "Predominant recognition of human T cell leukemia virus type I (HTLV-I) pX gene products by human $\mathrm{CD} 8^{+}$cytotoxic T cells directed against HTLV-I-infected cells," International Immunology, vol. 3, no. 8, pp. 761-767, 1991.

[15] C. E. Parker, S. Daenke, S. Nightingale, and C. R. M. Bangham, "Activated, HTLV-1-specific cytotoxic T-lymphocytes are found in healthy seropositives as well as in patients with tropical spastic paraparesis," Virology, vol. 188, no. 2, pp. 628636, 1992.

[16] C. Pique, F. Connan, J. P. Levilain, J. Choppin, and M. C. Dokhélar, "Among all human T-cell leukemia virus type 1 proteins, tax, polymerase, and envelope proteins are predicted as preferential targets for the HLA-A2- restricted cytotoxic Tcell response," Journal of Virology, vol. 70, no. 8, pp. 49194926, 1996.

[17] T. Jinnohara, M. Tsujisaki, S. Sasaki, Y. Hinoda, and K. Imai, "Cytotoxic activity in a case of adult T-cell leukemia/lymphoma with spontaneous regression," International Journal of Hematology, vol. 65, no. 3, pp. 293-298, 1997.

[18] S. Suzuki, K. Uozumi, M. Maeda et al., "Adult T-cell leukemia in a liver transplant recipient that did not progress after onset of graft rejection," International Journal of Hematology, vol. 83, no. 5, pp. 429-432, 2006.

[19] Y. Hoshida, T. Li, Z. Dong et al., "Lymphoproliferative disorders in renal transplant patients in Japan," International Journal of Cancer, vol. 91, no. 6, pp. 869-875, 2001.

[20] Y. Shimizu, A. Takamori, A. Utsunomiya et al., "Impaired taxspecific t-cell responses with insufficient control of HTLV-1 in a subgroup of individuals at asymptomatic and smoldering stages," Cancer Science, vol. 100, no. 3, pp. 481-489, 2009.

[21] T. Kozako, N. Arima, S. Toji et al., "Reduced frequency, diversity, and function of human T cell leukemia virus type 1specific $\mathrm{CD}^{+} \mathrm{T}$ cell in adult T cell leukemia patients," Journal of Immunology, vol. 177, no. 8, pp. 5718-5726, 2006.

[22] T. Kozako, M. Yoshimitsu, H. Fujiwara et al., "PD-1/PD-L1 expression in human T-cell leukemia virus type 1 carriers and adult T-cell leukemia/lymphoma patients," Leukemia, vol. 23, no. 2, pp. 375-382, 2009.

[23] B. Arnulf, M. Thorel, Y. Poirot et al., "Loss of the ex vivo but not the reinducible $\mathrm{CD} 8^{+} \mathrm{T}$-cell response to Tax in human $\mathrm{T}$ cell leukemia virus type 1-infected patients with adult T-cell leukemia/lymphoma," Leukemia, vol. 18, no. 1, pp. 126-132, 2004.
[24] M. Kannagi, K. Sugamura, and K. I. Kinoshita, "Specific cytolysis of fresh tumor cells by an autologous killer T cell line derived from an adult T cell leukemia/lymphoma patient," Journal of Immunology, vol. 133, no. 2, pp. 1037-1041, 1984.

[25] Y. Furukawa, R. Kubota, M. Tara, S. Izumo, and M. Osame, "Existence of escape mutant in HTLV-I tax during the development of adult T-cell leukemia," Blood, vol. 97, no. 4, pp. 987-993, 2001.

[26] Y. Furukawa, M. Tara, S. Izumo, K. Arimura, and M. Osame, "HTLV-I viral escape and host genetic changes in the development of adult T cell leukemia," International Journal of Cancer, vol. 118, no. 2, pp. 381-387, 2006.

[27] S. Tamiya, M. Matsuoka, K. I. Etoh et al., "Two types of defective human T-lymphotropic virus type I provirus in adult T-cell leukemia," Blood, vol. 88, no. 8, pp. 3065-3073, 1996.

[28] M. Miyazaki, J. I. Yasunaga, Y. Taniguchi, S. Tamiya, T. Nakahata, and M. Matsuoka, "Preferential selection of human Tcell leukemia virus type 1 provirus lacking the 5' long terminal repeat during oncogenesis," Journal of Virology, vol. 81, no. 11, pp. 5714-5723, 2007.

[29] A. Okayama, S. Stuver, M. Matsuoka et al., "Role of HTLV1 proviral DNA load and clonality in the development of adult T-cell leukemia/lymphoma in asymptomatic carriers," International Journal of Cancer, vol. 110, no. 4, pp. 621-625, 2004.

[30] R. Kubota, T. Kawanishi, H. Matsubara, A. Manns, and S. Jacobson, "HTLV-I specific IFN- $\gamma+\mathrm{CD}^{+}$lymphocytes correlate with the proviral load in peripheral blood of infected individuals," Journal of Neuroimmunology, vol. 102, no. 2, pp. 208-215, 2000.

[31] R. Kubota, M. Nagai, T. Kawanishi, M. Osame, and S. Jacobson, "Increased HTLV type 1 tax-specific $\mathrm{CD}^{+}$cells in HTLV type 1-associated myelopathy/tropical spastic paraparesis: correlation with HTLV type 1 proviral load," AIDS Research and Human Retroviruses, vol. 16, no. 16, pp. 1705-1709, 2000.

[32] D. Wodarz, S. E. Hall, K. Usuku et al., "Cytotoxic T-cell abundance and virus load in human immunodeficiency virus type 1 and human T-cell leukaemia virus type 1," Proceedings of the Royal Society B, vol. 268, no. 1473, pp. 1215-1221, 2001.

[33] C. R. Bangham, K. Meekings, F. Toulza et al., "The immune control of HTLV-1 infection: selection forces and dynamics," Frontiers in Bioscience, vol. 14, pp. 2889-2903, 2009.

[34] B. Asquith, A. J. Mosley, A. Barfield et al., "A functional CD8 ${ }^{+}$ cell assay reveals individual variation in $\mathrm{CD}^{+}$cell antiviral efficacy and explains differences in human T-lymphotropic virus type 1 proviral load," Journal of General Virology, vol. 86, part 5, pp. 1515-1523, 2005.

[35] T. Kattan, A. MacNamara, A. G. Rowan et al., "The avidity and lytic efficiency of the CTL response to HTLV-11," Journal of Immunology, vol. 182, no. 9, pp. 5723-5729, 2009.

[36] B. Asquith, Y. Zhang, A. J. Mosley et al., "In vivo T lymphocyte dynamics in humans and the impact of human Tlymphotropic virus 1 infection," Proceedings of the National Academy of Sciences of the United States of America, vol. 104, no. 19, pp. 8035-8040, 2007.

[37] K. J. M. Jeffery, K. Usuku, S. E. Hall et al., "HLA alleles determine human T-lymphotropic virus-I (HTLV-I) proviral load and the risk of HTLV-I-associated myelopathy," Proceedings of the National Academy of Sciences of the United States of America, vol. 96, no. 7, pp. 3848-3853, 1999.

[38] K. Bieganowska, P. Höllsberg, G. J. Buckle et al., "Direct analysis of viral-specific $\mathrm{CD}^{+} \mathrm{T}$ cells with soluble HLA- A2/ Tax11-19 tetramer complexes in patients with human $\mathrm{T}$ 
cell lymphotropic virus-associated myelopathy," Journal of Immunology, vol. 162, no. 3, pp. 1765-1771, 1999.

[39] S. Yashiki, T. Fujiyoshi, N. Arima et al., "HLA-A*26, HLA$\mathrm{B}^{*} 4002$, HLA-B* 4006 , and HLA-B* 4801 alleles predispose to adult $\mathrm{T}$ cell leukemia: the limited recognition of HTLV type 1 tax peptide anchor motifs and epitopes to generate anti-HTLV type 1 tax $\mathrm{CD}^{+}$cytotoxic T lymphocytes," AIDS Research and Human Retroviruses, vol. 17, no. 11, pp. 1047-1061, 2001.

[40] G. Gaudray, F. Gachon, J. Basbous, M. Biard-Piechaczyk, C. Devaux, and J. M. Mesnard, "The complementary strand of the human T-cell leukemia virus type 1 RNA genome encodes a bZIP transcription factor that down-regulates viral transcription," Journal of Virology, vol. 76, no. 24, pp. 1281312822, 2002.

[41] A. MacNamara, U. Kadolsky, C. R. M. Bangham, and B. Asquith, "T-cell epitope prediction: rescaling can mask biological variation between MHC molecules," PLoS Computational Biology, vol. 5, no. 3, Article ID e1000327, 2009.

[42] A. MacNamara, A. Rowan, S. Hilburn et al., "HLA class I binding of HBZ determines outcome in HTLV-1 infection," PLoS Pathogens, vol. 6, no. 9, Article ID e01117, 2010.

[43] S. Hilburn, A. Rowan, M.-A. Demontis et al., "In vivo expression of human T-lymphotropic virus type 1 basic leucinezipper protein generates specific $\mathrm{CD}^{+}$and $\mathrm{CD} 4^{+} \mathrm{T}$-lymphocyte responses that correlate with clinical outcome," Journal of Infectious Diseases, vol. 203, no. 4, pp. 529-536, 2011.

[44] K. Kurihara, N. Harashima, S. Hanabuchi et al., "Potential immunogenicity of adult T cell leukemia cells in vivo," International Journal of Cancer, vol. 114, no. 2, pp. 257-267, 2005.

[45] T. Kinoshita, M. Shimoyama, K. Tobinai et al., "Detection of mRNA for the tax1/rexl gene of human T-cell leukemia virus type I in fresh peripheral blood mononuclear cells of adult T-cell leukemia patients and viral carriers by using the polymerase chain reaction," Proceedings of the National Academy of Sciences of the United States of America, vol. 86, no. 14 , pp. 5620-5624, 1989.

[46] S. Takeda, M. Maeda, S. Morikawa et al., "Genetic and epigenetic inactivation of TAX gene in adult t-cell leukemia cells," International Journal of Cancer, vol. 109, no. 4, pp. 559$567,2004$.

[47] T. Ohashi, S. Hanabuchi, H. Kato et al., "Prevention of adult T-cell leukemia-like lymphoproliferative disease in rats by adoptively transferred $\mathrm{T}$ cells from a donor immunized with human T-cell leukemia virus type 1 Tax-coding DNA vaccine," Journal of Virology, vol. 74, no. 20, pp. 9610-9616, 2000.

[48] S. Hanabuchi, T. Ohashi, Y. Koya et al., "Regression of human T-cell leukemia virus type I (HTLV-I)-associated lymphomas in a rat model: peptide-induced T-cell immunity," Journal of the National Cancer Institute, vol. 93, no. 23, pp. 1775-1783, 2001.

[49] N. Harashima, K. Kurihara, A. Utsunomiya et al., "Graftversus-Tax Response in adult T-cell leukemia patients after hematopoietic stem cell transplantation," Cancer Research, vol. 64, no. 1, pp. 391-399, 2004.

[50] N. Harashima, R. Tanosaki, Y. Shimizu et al., "Identification of two new HLA-A*1101-restricted tax epitopes recognized by cytotoxic $\mathrm{T}$ lymphocytes in an adult T-cell leukemia patient after hematopoietic stem cell transplantation," Journal of Virology, vol. 79, no. 15, pp. 10088-10092, 2005.

[51] M. Saito, T. Matsuzaki, Y. Satou et al., "In vivo expression of the HBZ gene of HTLV-1 correlates with proviral load, inflammatory markers and disease severity in HTLV-1 associated myelopathy/tropical spastic paraparesis (HAM/TSP)," Retrovirology, vol. 6, article 19, 2009.
[52] Y. Satou, J. I. Yasunaga, M. Yoshida, and M. Matsuoka, "HTLV-I basic leucine zipper factor gene mRNA supports proliferation of adult T cell leukemia cells," Proceedings of the National Academy of Sciences of the United States of America, vol. 103, no. 3, pp. 720-725, 2006.

[53] K. Suemori, H. Fujiwara, T. Ochi et al., "HBZ is an immunogenic protein, but not a target antigen for human $\mathrm{T}$ cell leukemia virus type 1-specific cytotoxic T lymphocytes," Journal of General Virology, vol. 90, part 8, pp. 1806-1811, 2009.

[54] F. Rende, I. Cavallari, A. Corradin et al., "Kinetics and intracellular compartmentalization of HTLV-1 gene expression: nuclear retention of HBZ mRNAs," Blood, vol. 117, no. 18, pp. 4855-4859, 2011.

[55] M. Matsuoka and K. T. Jeang, "Human T-cell leukemia virus type 1 (HTLV-1) and leukemic transformation: viral infectivity, Tax, HBZ and therapy," Oncogene, vol. 30, no. 12, pp. 13791389, 2010.

[56] Y. Satou, J.-I. Yasunaga, T. Zhao et al., "HTLV-1 bZIP factor induces T-cell lymphoma and systemic inflammation in vivo," PLoS Pathogens, vol. 7, no. 2, Article ID e1001274, 2011.

[57] R. Sundaram, M. P. Lynch, S. Rawale et al., "Protective efficacy of multiepitope human leukocyte antigen-A*0201 restricted cytotoxic T-lymphocyte peptide construct against challenge with human T-cell lymphotropic virus type 1 Tax recombinant vaccinia virus," Journal of Acquired Immune Deficiency Syndromes, vol. 37, no. 3, pp. 1329-1339, 2004.

[58] R. Sundaram, Y. Sun, C. M. Walker, F. A. Lemonnier, S. Jacobson, and P. T. P. Kaumaya, "A novel multivalent human CTL peptide construct elicits robust cellular immune responses in HLA-A*0201 transgenic mice: implications for HTLV-1 vaccine design," Vaccine, vol. 21, no. 21-22, pp. 2767-2781, 2003.

[59] Y. Taniguchi, K. Nosaka, J. I. Yasunaga et al., "Silencing of human T-cell leukemia virus type I gene transcription by epigenetic mechanisms," Retrovirology, vol. 2, article 64, 2005.

[60] T. Koiwa, A. Hamano-Usami, T. Ishida et al., “5'-long terminal repeat-selective CpG methylation of latent human T-cell leukemia virus type 1 provirus in vitro and in vivo," Journal of Virology, vol. 76, no. 18, pp. 9389-9397, 2002. 


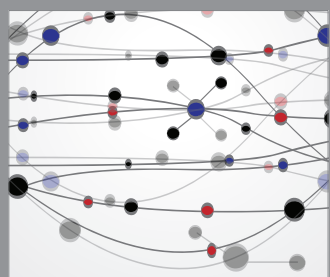

The Scientific World Journal
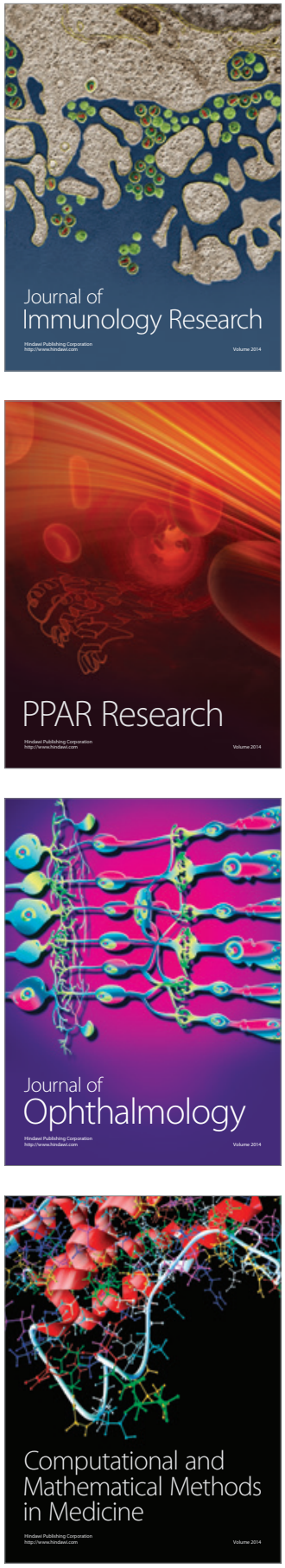

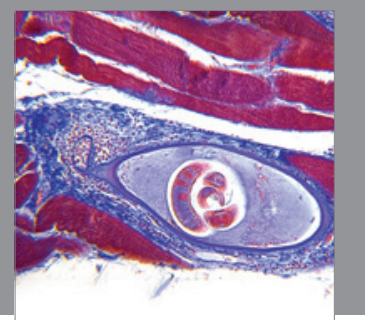

Gastroenterology

Research and Practice
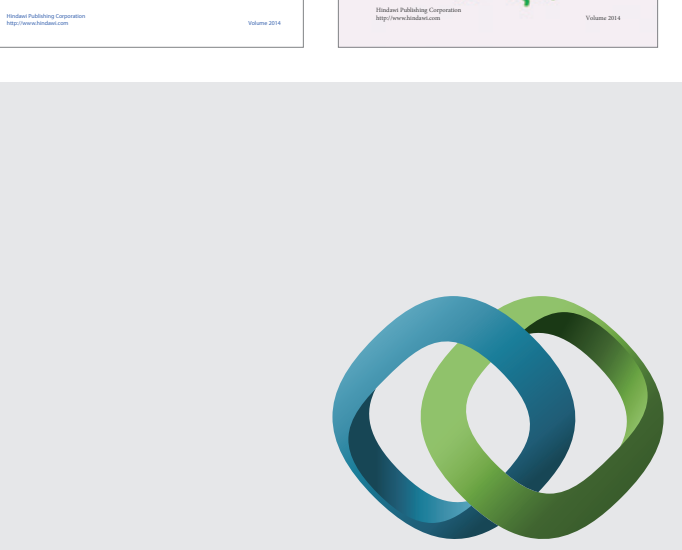

\section{Hindawi}

Submit your manuscripts at

http://www.hindawi.com
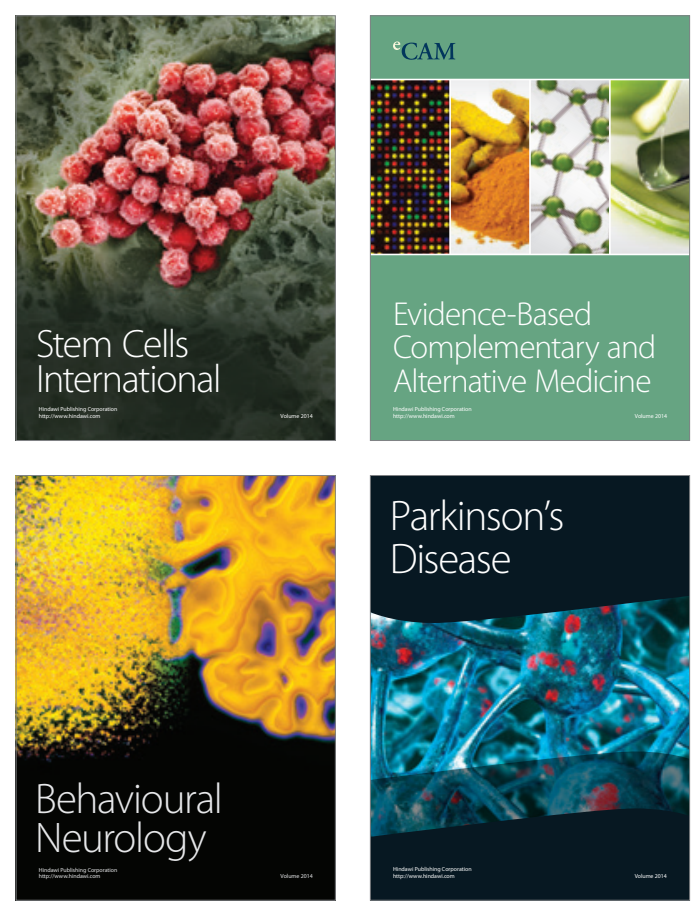

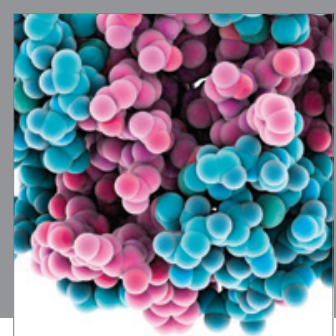

Journal of
Diabetes Research

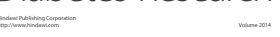

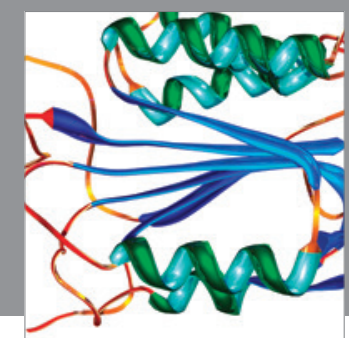

Disease Markers
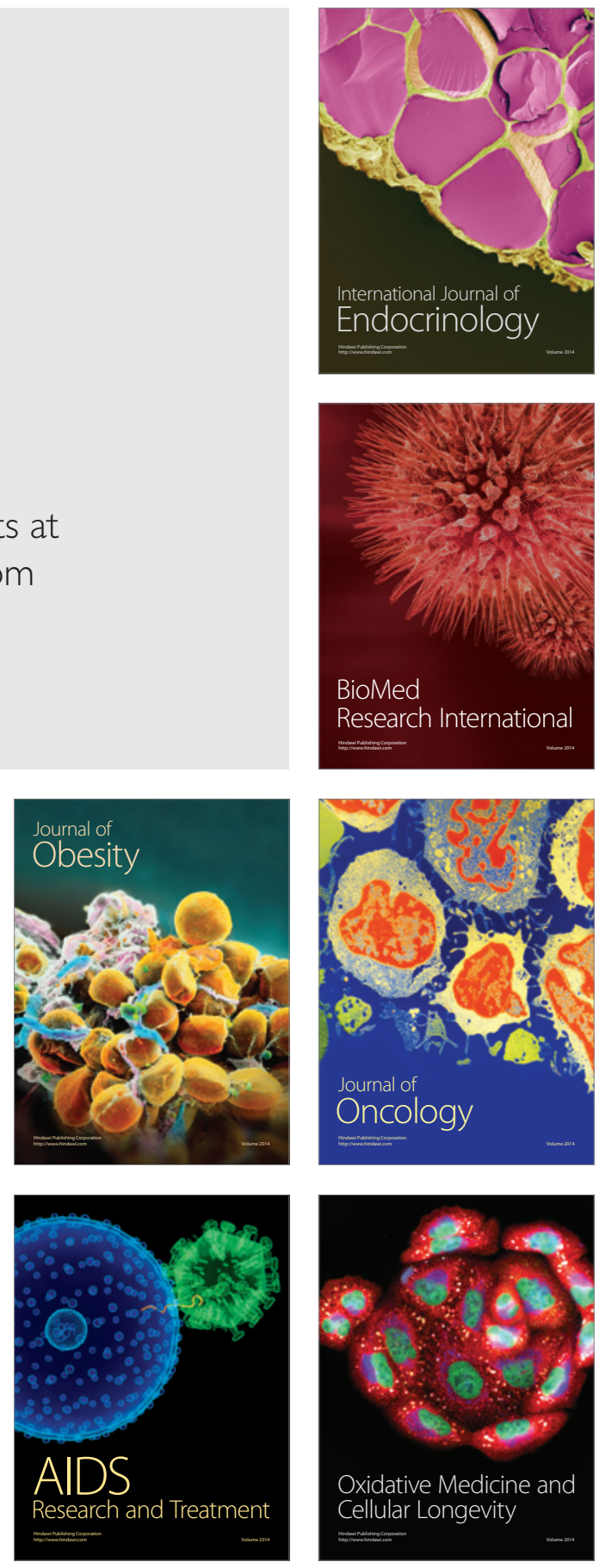